\title{
OS DETERMINANTES DA QUALIDADE DA GOVERNANÇA PRATICADA PELAS COMPANHIAS ABERTAS BRASILEIRAS ${ }^{1}$
}

\author{
THE DETERMINANTS OF GOOD GOVERNANCE PRACTICED BY BRAZILIAN \\ LISTED COMPANIES
}

\begin{abstract}
Valdir de Jesus Lameira ${ }^{2}$ Walter Lee Ness, $\mathrm{Jr}^{3}$

RESUMO: Nesta pesquisa procurou-se estimar a qualidade da governança praticada por uma amostra significativa de companhias abertas brasileiras, por meio de um índice composto por 20 perguntas de respostas binárias, no período entre 2003 e 2008, e relacioná-la a alguns fatores que pudessem ser determinantes da qualidade da governança praticada. Foram utilizados diversos novos fatores associados ao desempenho como o ebit-to-sales, o market-to-sales, o return on assets e o return on equity, e diferentes fatores relacionados com o risco como o beta local, o beta obtido com o uso do S\&P 500, a volatilidade das ações das empresas, o risco idiossincrático, e o custo implícito do capital. Diversas outras variáveis, advindas da revisão bibliográfica, também foram inseridas de modo a ampliar o espectro de fatores que podem impactar a qualidade de governança das empresas. Verificou-se que o tempo de experiência societária e a participação no Nível 2 ou Novo Mercado da Bovespa são novos fatores observados como geradores de impacto na qualidade da governança praticada. Melhores níveis de governança também estão associados a melhores desempenhos e menores riscos. Os resultados conseguidos por meio da aplicação do método das regressões lineares foram confirmados pelos resultados obtidos com o uso do método das equações estruturais. Observou-se endogeneidade que não invalidou os resultados obtidos com o uso das regressões lineares.
\end{abstract}

PALAVRAS-CHAVE: Governança, risco, desempenho, companhias abertas, regressões lineares e equações estruturais.

ABSTRACT: This study estimated the quality of governance practiced by a significant sample of Brazilian publicly traded companies between 2003 and 2008, and related it to some variables in order to identify which of them are relevant in the quality of governance. An index composed of twenty questions, with all answers in binary form, was constructed to measure the quality of governance. The results were obtained through the application of the method of simple and multiple linear regressions and by the use of structural equations.

It was found that the greater dispersion of holdings of ordinary shares, the greater investment by the controlling shareholder in total capital, lesser degrees of tangible assets, larger boards of directors, lower operating and financial leverage, lower risk, higher margins, the existence of a ADR level 2 or 3 program, more experience in been a public company, greatest volume of assets, and participation in the Level 2 or Bovespa's New Market's correlate positively with the quality of governance practiced by the Brazilian publicly traded companies.

Keywords: Governance, determinants of governance, Brazilian public companies, linear regressions and structural equations.

\footnotetext{
${ }^{1}$ Artigo Recebido em 17.02.2009. Revisado por pares em 25.07.2011. Recomendado em 28.07.2011 por Leomar dos Santos Editor. Publicado em 26.01.2012.

Organização Responsável pelo periódico: Universidade regional de Blumenau - FURB - www.furb.br/rn

${ }^{2}$ Instituto de Engenharia de Sistemas e Computadores - Coimbra - INESC- vlameira@uol.com.br

${ }^{3}$ Pontifícia Universidade Católica - PUC-RJ - ness@iag.puc-rio.br
}

Revista de Negócios, ISSN 1980-4431, Blumenau, v16, n.3, p.33 - 52, Julho/Setembro 2011. 


\section{INTRODUÇÃO}

Nos mercados de crédito e de capitais, segurança e potencial de crescimento são pontos importantes para a captação de recursos por parte das empresas. Entre outros aspectos, esse potencial de crescimento das organizações está ligado ao montante de recursos disponíveis para o investimento e à capacidade de geração de um fluxo atrativo de retornos para os investidores. Por outro lado, a segurança percebida no investimento e o baixo custo para monitorá-lo são aspectos também relevantes na perspectiva dos investidores e demais participantes do mercado.

As pesquisas sobre governança corporativa têm inserido alguns novos aspectos entre o conjunto de fatores a serem analisados para a tomada de decisão por parte dos investidores, como: a) a estrutura de propriedade e controle da empresa; b) o ambiente de negócios corporativos onde a empresa atua; c) o ambiente regulatório; d) a capacidade de enforcement existente; e) a política de incentivos praticada pela empresa em relação aos administradores; e f) algumas características específicas de cada organização, como a forma de estruturação do conselho de administração, a existência e atuação de comitês, a possibilidade de tag along, por exemplo.

Assim sendo, o aprimoramento das práticas de governança pode ser associado ao desenvolvimento de melhores estruturas organizacionais e à busca de uma melhor dinâmica no seu funcionamento.

Ao longo dos últimos anos, em meio ao processo de globalização dos mercados financeiros e de produtos, várias empresas brasileiras promoveram melhoria das suas práticas de governança de modo a captarem recursos nos mercados de crédito e capitais internacionais. Uma das maneiras dessas empresas mostrarem-se aptas para receberem o aporte de recursos estrangeiros foi a promoção de programas de ADR níveis 2 ou 3 para negociação das ações da companhia no mercado de capitais norte-americano. No mercado interno, diversas companhias abertas promoveram melhoria de seu sistema de governança de modo a captar recursos mais baratos e em maior volume no mercado de capitais nacional. Para mostrarem-se mais seguras para o ingresso de novos acionistas, ingressaram nos Níveis Diferenciados de Governança Corporativa (NDGC), incluindo entre estes o Novo Mercado da Bolsa de Valores de São Paulo (Bovespa).

É desse modo que as companhias abertas nacionais se inseriram no ambiente global contemporâneo, em que se buscam soluções para a melhoria da gestão organizacional de modo que os efeitos afetem positivamente o desempenho da empresa e possibilitem o aumento do retorno das suas ações. Assumindo-se que a meta almejada por essas companhias é o crescimento do retorno dos acionistas e utilizando-se o valor da companhia como objetivo a ser maximizado, essas organizações devem buscar como objetivos intermediários, a redução dos custos de capital próprio e de terceiros e a melhoria do desempenho operacional. Nesse ambiente, o exercício de melhores práticas de governança torna-se um dos instrumentos que podem permitir a melhoria do processo de decisão nas empresas, além de proporcionar o aperfeiçoamento dos controles e uma maior eficiência gerencial, e assim viabilizar o atingimento dessas metas intermediárias. 


\section{OS DETERMINANTES DA QUALIDADE DA GOVERNANÇA PRATICADA PELAS COMPANHIAS ABERTAS BRASILEIRAS}

Nesse contexto identifica-se a seguinte situação problema: quais são os fatores que estão associados a melhores níveis de governança corporativa praticada pelas companhias abertas brasileiras? Foi investigada, ainda, a possível endogeneidade entre a variável de governança e os fatores determinantes dessa variável.

$\mathrm{Na}$ segunda seção desenvolve-se um referencial teórico que suporta a construção do índice amplo de governança e a escolha dos fatores determinantes de modo a se estabelecer relações entre essas variáveis. Na terceira seção apresenta-se a metodologia de pesquisa por meio da qual podemos ligar o índice de governança aos fatores determinantes de sua qualidade. $\mathrm{Na}$ quarta seção é promovida uma análise dos resultados. Na quinta seção são evidenciadas as conclusões que a pesquisa proporcionou, relacionando alguns resultados obtidos com estudos precursores. Na última seção relacionam-se as referências que foram utilizadas como fonte de pesquisa.

\section{REFERENCIAL TEÓRICO}

\section{1 - Qualidade da governança praticada}

A teoria econômica evidencia que um dos principais problemas existentes nas grandes corporações modernas é a separação entre propriedade e controle, que possibilita a geração de conflitos de interesses entre acionistas e administradores ou entre controladores e minoritários. É nesse contexto que atua a governança corporativa, sendo o principal objetivo da aplicação desse conjunto de praticas, a promoção de um ambiente de negócios onde estejam minimizados os conflitos de interesses mencionados e as possibilidades de expropriação dos direitos de propriedade dos investidores.

Em seu sentido mais amplo, governança corporativa está relacionada com a minoração dos efeitos advindos dos conflitos de agência mencionados por Berle e Means (1933); com a diminuição dos custos de gerenciamento dos recursos na empresa, como destacou Coase (1937); com a redução da possibilidade de ocorrência de comportamentos oportunistas, como salientaram Alchian e Demsetz (1972); e com a melhoria do controle dos ativos em conformidade ao pensamento de Williamson (1975).

Assim sendo, o aprimoramento das práticas de governança está associado ao desenvolvimento de melhores estruturas organizacionais e a busca de uma melhor dinâmica no seu funcionamento, o que deve possibilitar o aumento da eficiência das empresas, queda nos riscos e, em consequência, uma melhor avaliação por parte do mercado.

Percebe-se que a adequação e o aperfeiçoamento das práticas de governança é um processo contínuo ao longo do tempo, motivado por estímulos internos ou pressões externas às organizações. Um exemplo recente de pressão externa exercida sob as empresas foi a necessidade de atendimento às exigencias do Sarbanes-Oxley Act, de 30 de julho de 2002, por parte das companhias abertas brasileiras, que promoveram programas de American Depositary Receipts (ADR) níveis 2 e 3 para negociação de suas ações no mercado de capitais norte-americano. 
Nos últimos anos, as pesquisas sobre governança passaram a incorporar a utilização de índices amplos de governança de modo a se investigar relações entre essa e outras variáveis, dentre as quais o valor das companhias foi a que obteve maior destaque.

Os estudos mais recentes dispõem sobre um conjunto de aspectos relacionados com governança, entre os quais podem ser destacados: a) a relevância das características das estruturas de propriedade e controle das companhias; b) o nível de disclosure das informações; c) a existência de benefícios privados advindos do controle; d) a qualidade da auditoria; e) a existência de conselho fiscal e comitês; f) a composição do conselho de administração; g) a política de remuneração da empresa; h) a existência de investidor institucional ativista; i) a possibilidade de tag along para os minoritários; j) a existência de provisões anti-takeovers; k) o nível de proteção aos direitos dos minoritários; e 1) o nível de desenvolvimento do mercado financeiro.

A diferenciação das empresas por meio de pontuação relativa aos tópicos retromencionados proporciona um entendimento dos possíveis estágios em que as empresas podem se situar em relação às práticas de governança que utilizam. Dessa forma, implementou-se a mensuração da qualidade da governança praticada pelas empresas, utilizando-se para isso de um índice amplo de governança cujas questões componentes e critérios para pontuação se encontram dispostas no Apêndice. A racionalidade das questões foi a mesma utilizada nas referências de origem.

\section{2 - Desempenho: conceitos e indicadores}

No Brasil, ainda são poucos os que estudaram os possíveis determinantes da qualidade da governança praticada pelas companhias. Como o estudo em questão insere uma perspectiva ampliada dos trabalhos de Da Silveira et al. (2007) e Da Silveira (2004), decidiu-se começar a estudar o tema pela busca de indicadores de desempenho. Assim, uma das fontes estabelecidas para a escolha dos indicadores recaiu sobre Da Silva (2002), que em suas recomendações, deixa como alternativa para futuras pesquisas a investigação da relação entre governança e desempenho, este mensurado pelos indicadores retorno dos ativos (return on assets - ROA) e retorno do acionista (return on equity - ROE).

A dimensão desempenho da empresa foi mensurada por alguns indicadores contábeis, financeiros e de mercado, pois se assume nesta pesquisa o pensamento de Rowe e Morrow Jr. (1999), segundo os quais, o desempenho de uma empresa nas pesquisas deve ser explicitado por mais de uma variável. Para os referidos autores, não está claro se as variáveis advindas das demonstrações contábeis e financeiras, dos valores de mercado ou ainda outras medidas subjetivas de performance são simplesmente três métodos distintos de se operacionalizar o construto desempenho, ou se esses métodos representam dimensões distintas da performance da empresa. Dessa forma, entendem que o construto desempenho seja multidimensional.

Assim, o desempenho foi mensurado a partir de indicadores que utilizaram dados das demonstrações financeiras da companhia (DF), de suas informações trimestrais (ITR) ou dos 


\section{OS DETERMINANTES DA QUALIDADE DA GOVERNANÇA PRATICADA PELAS COMPANHIAS ABERTAS BRASILEIRAS}

valores de mercado relativos às ações da empresa. São medidas de desempenho: a) o retorno dos acionistas - return on equity (ROE); b) o retorno operacional - return on assets (ROA); c) a razão entre valor de mercado das ações e o valor de vendas (receita líquida de vendas) - market-tosales ratio (MTS); e d) a razão entre o lucro operacional (earnings before interest and taxes EBIT) e a receita líquida de vendas - ebit-to-sales ratio (ETS).

A utilização do indicador MTS ocorreu em função dos resultados obtidos por Black et al. (2006). A razão ETS foi o mais estável indicador de performance ao longo do tempo, conforme evidenciaram Bhagat e Jefferis Jr. (2005). Dessa forma, espera-se que os resultados das relações estatísticas envolvendo esse indicador sejam significativos. Ainda segundo esses autores, os indicadores ROE e ROA são variáveis bastante relevantes na investigação do impacto da governança no desempenho das empresas. Assim sendo, incluíram-se também esses retornos como indicadores de performance.

\section{3 - Risco: conceitos e indicadores}

Definiu-se o risco da empresa como uma medida relativa à distribuição dos retornos das ações da empresa no mercado. Utilizaram-se indicadores calculados a partir da coleta de dados em diversos períodos de tempo (betas, volatilidade e risco idiossincrático) ou a partir de dados coletados em apenas dois períodos de tempo distintos (taxa de desconto do preço das ações ou custo implícito de capital das empresas). Entende-se, segundo Estrada (2000), que o risco pode ser mensurado por diversas variáveis com relativa eficiência, e alguns parâmetros tradicionais como o beta ( $\beta$ ) do Capital Asset Pricing Model (CAPM) - não se mostram tão bons estimadores de risco em mercados emergentes. Além disso, os indicadores utilizados para representarem o risco podem ser encarados como dimensões distintas da referida variável, em vista de sua perspectiva multidimensional.

Outros motivos para a inclusão de outros estimadores de risco diferentes dos betas das ações das empresas são: a) os betas locais são obtidos regredindo os retornos da ação contra um índice que é concentrado em poucas ações e setores da economia, podendo resultar em um valor de baixo conteúdo informacional; b) as distribuições de retornos não são simétricas e normais, mas log-normais, por isso a variância não é a melhor medida de risco; c) existe um pequeno número de companhias abertas nos mercados emergentes; e d) os betas obtidos em alguns mercados emergentes são pequenos, não refletindo adequadamente o risco das empresas e gerando custos de capital incompatíveis com os que seriam razoáveis de serem esperados.

Portanto, incluiu-se nessa relação de variáveis, além do beta local (doravante também designado de betalocal); o beta S\&P 500 (doravante também denominado de betasp) da empresa, obtido a partir da regressão dos retornos da ação da companhia contra os retornos do mercado americano medidos pelo índice Standard \& Poor's 500 - S\&P 500; a volatilidade dos retornos das ações (doravante volat); o risco idiossincrático ou residual (doravante idios), cujo indicador pode ser estimado pelo desvio padrão da distribuição da diferença entre os retornos acontecidos e os retornos esperados com o uso do beta local (betalocal) e do beta S\&P 500 (betasp) das 
empresas, em conformidade ao desenvolvido por Derwall e Verwijmeren (2007); e o custo médio ponderado de capital (weighted average cost of capital - doravante também denominado por wacc), inserido na pesquisa de modo a servir como uma proxy do custo implícito de capital assumido por Ashbaugh et al. (2004).

Esse custo implícito de capital, que se assume possível de ser adequadamente mensurado por uma proxy do retorno exigido pelo investidor sobre as ações da companhia, pode ser calculado como o wacc da empresa no ano posterior ao que se está inferindo sobre o custo implícito. Esse parâmetro - wacc - substitui o custo implícito utilizado em algumas pesquisas, como é o caso do estudo de Ashbaugh et al. (2004). No estudo mencionado, essa variável é calculada utilizando-se previsões de preço da ação da empresa feitas por analistas de mercado e obtendo-se a taxa de desconto que faz com que esse valor futuro se iguale ao valor presente observado no mercado, na época. Nesta pesquisa utiliza-se o wacc devido às dificuldades de se conseguirem targets de preço de anos anteriores para as ações da amostra.

O wacc pode ser calculado a partir dos dados da demonstração financeira utilizando-se o modelo de avaliação em um estágio, conforme Damodaran (2002). Para maior transparência, evidencia-se a fórmula de cálculo a seguir.

$\mathrm{WACC}=\{[$ EBIT $\cdot(1-\mathrm{T})+\mathrm{D}-\mathrm{I} /($ EQUITY + DEBT $)] *[1+(1-$ Payout $) \mathrm{x}$ ROA $]\}+[1+(1-$ Payout $) \times$ ROA $)]$

Deve se destacar que essa variável assume sempre a defasagem temporal de um ano à frente do ano pesquisado. Da mesma forma que as variáveis anteriores, essa variável é usada no sentido de se conseguir inferências a respeito de possíveis relações envolvendo governança e risco.

\section{4 - Outras Variáveis relacionadas com Governança}

Nesta pesquisa, são inseridas diversas variáveis possivelmente relacionadas a qualidade da governança praticada, de modo a se ampliar o conhecimento relativo aos fatores que podem diferenciar as empresas em vista de suas práticas de governança corporativa. Tal prática tem como objetivo possibilitar a obtenção de resultados que possam direcionar e dimensionar adequadamente a relação entre qualidade de governança e seus fatores determinantes. Portanto, foram incluídas as seguintes variáveis: a) percentual de imobilização dos ativos (imob), calculado como a razão entre o ativo permanente e o ativo total; b) alavancagem operacional (aop), calculado como a razão entre os resultados operacionais e as receitas operacionais ocorridos entre anos consecutivos; c) relação entre endividamento e capital (de), calculado como a razão entre o endividamento líquido da empresa e seu capital social; d) tamanho da empresa (tam), calculado como o logaritmo da receita operacional líquida da empresa; e) nível de investimentos (inv), calculado como a razão entre o saldo da conta investimentos e o montante do patrimônio líquido; 


\section{OS DETERMINANTES DA QUALIDADE DA GOVERNANÇA PRATICADA PELAS COMPANHIAS ABERTAS BRASILEIRAS}

f) alavancagem financeira (afin), calculada como a razão entre o lucro por ação e o resultado operacional ocorrido entre anos consecutivos; g) liquidez das ações em mercado (liq), valor retirado do banco de dados da Economática; h) market-to-book value (mtbv), calculado como a razão entre o valor de mercado e o valor contábil do equity; i) experiência societária (exp), calculada como o logaritmo do número de meses que a companhia é aberta e tem suas ações listadas em bolsa de valores; j) tamanho do conselho de administração (log cons), calculado como o logaritmo do tamanho do conselho; k) dummy de controle privado nacional (pri) - 0 se é estatal e 1 se possui outra estrutura de controle privado nacional; 1) dummy de existência de programa de American Depositary Receipts (ADR) níveis 2 ou 3 - ADR 23 (adr23) - 0 se não tem e 1 se tem; m) dummy de participação no nível 2 ou Novo Mercado da Bovespa - N2 e NM (n2nm) - 0 se não tem e 1 se tem; n) dummy de participação no N2 e NM e concomitante existência de programas de ADR23 (n2nmadr23) - 0 se não tem e 1 se tem; o) percentual de ordinárias do controlador (ord), calculado como a razão entre o número de ações ordinárias do controlador e o total de ações ordinárias da empresa; e p) percentual do capital total do controlador (cap), calculado como a razão entre o número de ações do controlador e o total de ações da empresa.

\section{METODOLOGIA}

\section{1 - Aspectos da pesquisa}

O universo de unidades amostrais é composto por companhias abertas brasileiras não financeiras com ações negociadas na Bovespa e regularmente registradas na Comissão de Valores Mobiliários (CVM) em 31.3.2003, 31.3.2004, 31.3.2005, 31.3.2006, 31.3.2007 e 31.3.2008. O número de companhias abertas nos anos mencionados era de respectivamente 780 (2003), 695 (2004), 627 (2005), 620 (2006), 682 (2007) e 687 (2008) sociedades anônimas. Desse total compuseram nossa amostra 55 (2003), 59 (2004), 65 (2005), 74 (2006), 87 (2007) e 114 (2008) companhias abertas.

A amostra, não probabilística, investigada é composta apenas de empresas cujas ações, listadas na Bovespa, apresentaram liquidez e volatilidade diferentes de zero (0) nos meses de abril dos anos 2003, 2004, 2005, 2006, 2007 e 2008. Escolheu-se o mês de abril por ser o período em que as companhias abertas publicam suas demonstrações financeiras anuais e realizam suas assembléias gerais. Utiliza-se como segundo critério somente incluir empresas cujas ações tenham movimentado um volume financeiro de negócios em bolsa igual ou superior a 0,01\% do volume financeiro dos negócios envolvendo as ações da empresa de maior negociação na Bovespa, no período de tempo considerado.

Para a elaboração da pesquisa, foram utilizados dados secundários coletados de forma telematizada junto à Economática e uma pesquisa documental nas demonstrações financeiras (DF) e informativos anuais (IAN) obtidos junto aos sites da CVM, da Bovespa, das companhias e do banco J. P. Morgan, no tocante aos ADR. A partir da investigação desses documentos, foram respondidas as perguntas selecionadas para a construção do índice de governança. As respostas às perguntas devem ser do tipo SIM / NÃO. Quando a resposta for SIM, marca-se 1 ponto no 
quesito, e quando for NÃO, marca-se 0 (zero) no quesito. Ao final soma-se o total de pontos atribuídos a cada uma das empresas pesquisadas.

O índice utilizado foi criado pelo IBGC, via consulta a acadêmicos e profissionais, em 2005, no sentido de mensurar a qualidade das empresas abertas brasileiras de modo a premia-las com o prêmio IGBC de governança de 2005. Os resultados para a variável dependente denominada de índice de governança corporativa pode ser visualizado na tabela 1, a seguir.

Tabela 1: Características da variável dependente

Fonte: Os autores

\begin{tabular}{|c|c|c|c|c|c|c|c|}
\hline \multicolumn{2}{|c|}{} & Média & Mediana & Desvio-padrão & Mínimo & Máximo & No empresas $^{\text {o }}$ \\
\hline \multirow{5}{*}{ IGOV } & 2003 & 9,11 & 9 & 1,56 & 5 & 13 & 55 \\
\cline { 2 - 8 } & 2004 & 9,59 & 10 & 1,73 & 5 & 14 & 59 \\
\cline { 2 - 8 } & 2005 & 9,82 & 10 & 1,84 & 5 & 14 & 65 \\
\cline { 2 - 8 } & 2006 & 10,03 & 10 & 1,91 & 6 & 14 & 74 \\
\cline { 2 - 8 } & 2007 & 10,37 & 11 & 2,28 & 5 & 15 & 87 \\
\cline { 2 - 8 } & 2008 & 10,51 & 11 & 2,11 & 5 & 15 & 114 \\
\hline
\end{tabular}

O tratamento quantitativo pressupõe a utilização do método da regressão linear (simples e múltipla) e do método das equações estruturais. Para a realização dos testes estatísticos, foram utilizados os softwares E-views versão 5.0 e AMOS 6.0.

Entre as limitações da pesquisa estão: a) problemas de endogeneidade nas variáveis assumidas como exógenas. Para evitar esse problema pode ser utilizado o método das equações estruturais; b) podem existir problemas de não-normalidade nas distribuições das variáveis independentes, controlados por meio de transformações nas variáveis que não passarem no teste de normalidade; c) é possível que existam correlações significativas entre as variáveis independentes. Nesse sentido, podem ser promovidas transformações dessas variáveis (utilizando o logaritmo natural ou neperiano, a função inversa ou a operação de radiciação), ou ainda se decidir pela exclusão da variável; d) podem existir problemas de multicolinearidade, possíveis de serem resolvidos com a transformação das variáveis ou a eliminação de uma delas; e) podem existir problemas de identificação de causalidade ou mesmo uma relação de causalidade reversa entre governança e risco, passíveis de serem minimizados pelo uso do método das equações estruturais; e f) podem existir problemas na seleção da amostra, tendo em vista que no segmento das companhias abertas podem estar incluídas as empresas com maior rentabilidade.

\section{2 - Métodos Utilizados}

Para a investigação proposta foram utilizados os métodos das regressões lineares múltiplas e o método das equações estruturais. A equação genérica usada em ambos os métodos foi do tipo: 


\section{OS DETERMINANTES DA QUALIDADE DA GOVERNANÇA PRATICADA PELAS}

COMPANHIAS ABERTAS BRASILEIRAS

GOVERNANÇA $($ IGC $)=\beta 0+\beta 1$. RISCO $+\beta 2$. DESEMPENHO $+\beta \mathrm{i} . \mathrm{V} \mathrm{i}+\varepsilon$

Em que:

GOVERNANÇA $(\mathrm{IGC})$ = variável índice de governança corporativa mensurada a partir das respostas para as perguntas elencadas no Apêndice;

$\beta 0=$ termo constante da regressão linear;

$\beta 1=$ coeficiente do termo relacionado ao índice de governança e que representa o impacto que a variável de RISCO provoca na variável dependente;

RISCO = variável dependente cujos indicadores são o beta local (betalocal); o beta medido contra o S\&P 500 (betasp); a volatilidade da distribuição original de retornos das ações (volat); e o risco idiossincrático (idios), que é assumido nesta pesquisa como o desvio padrão da distribuição da diferença entre os retornos ocorridos e os retornos teóricos calculados por meio do CAPM local, e wacc;

$\beta 2$ = coeficiente do termo relacionado ao índice de governança e que representa o impacto que a variável de RISCO provoca na variável dependente;

DESEMPENHO = variável dependente cujos indicadores são o roa (return on assets), o roe (return on equity), o mts (market-to-sales ratio) e o ets (ebit-to-sales ratio);

$\beta \mathrm{i}=$ coeficientes dos termos relacionados às outras varáveis e que representam o impacto que essas variáveis provocam na variável dependente;

$\mathrm{Vi}$ = variáveis que podem apresentar poder explanatório sobre a variável dependente estudada;

$\varepsilon \mathrm{i}=$ termo de erro de cada função;

$\mathrm{i}=\{\mathrm{x} \in \mathrm{R} / 1<\mathrm{x}<5\}$.

O modelo final, já contando com as transformações das variáveis devido à necessidade de atendimento às premissas dos métodos, e que foi testado por meio do método das regressões lineares e pelo método das equações estruturais foi:

$\mathrm{SQR}(\mathrm{IGC})=\beta 0+\beta 1 . \mathrm{SQR}(\mathrm{BETALOCAL})+\beta 2 . \mathrm{SQR}(\mathrm{BETASP})+\beta 3 . \mathrm{LOG}$ $($ IDIOS $)+\beta 4$. LOG (VOLAT) $+\beta 5 . \mathrm{SQR}($ WACC $)+\beta 6$. LOG (ETS) $+\beta 7$. LOG $(\mathrm{MTS})+\beta 8 . \mathrm{SQR}(\mathrm{ROA})+\beta$. SQR $(\mathrm{ROE})+\beta 10 . \mathrm{LOG}(\mathrm{CAP})+\beta 11 . \mathrm{SQR}(\mathrm{ORD})+$ $\beta 12 . \mathrm{IMOB}+\beta 13$. LOG (INV) $+\beta 14$. LOG (EXP) $+\beta 15$. ADR23 $+\beta 16 . \mathrm{N} 2 \mathrm{NM}+$ B 17. N2NMADR23 $+\beta 18$. LOG (CONS) $+\beta 19$. PRI $+\beta 20$. TAM $+\beta 21$. LOG $(\mathrm{AFIN})+\beta 22 . \mathrm{LOG}(\mathrm{AOP})+\beta 23 . \mathrm{LOG}(\mathrm{DE})+\beta 24 . \mathrm{LOG}(\mathrm{MTBV})+\varepsilon$

A Figura 1 representa o diagrama de caminhos do modelo de estudo dos determinantes da governança corporativa das companhias investigadas que utiliza o método das equações estruturais. 


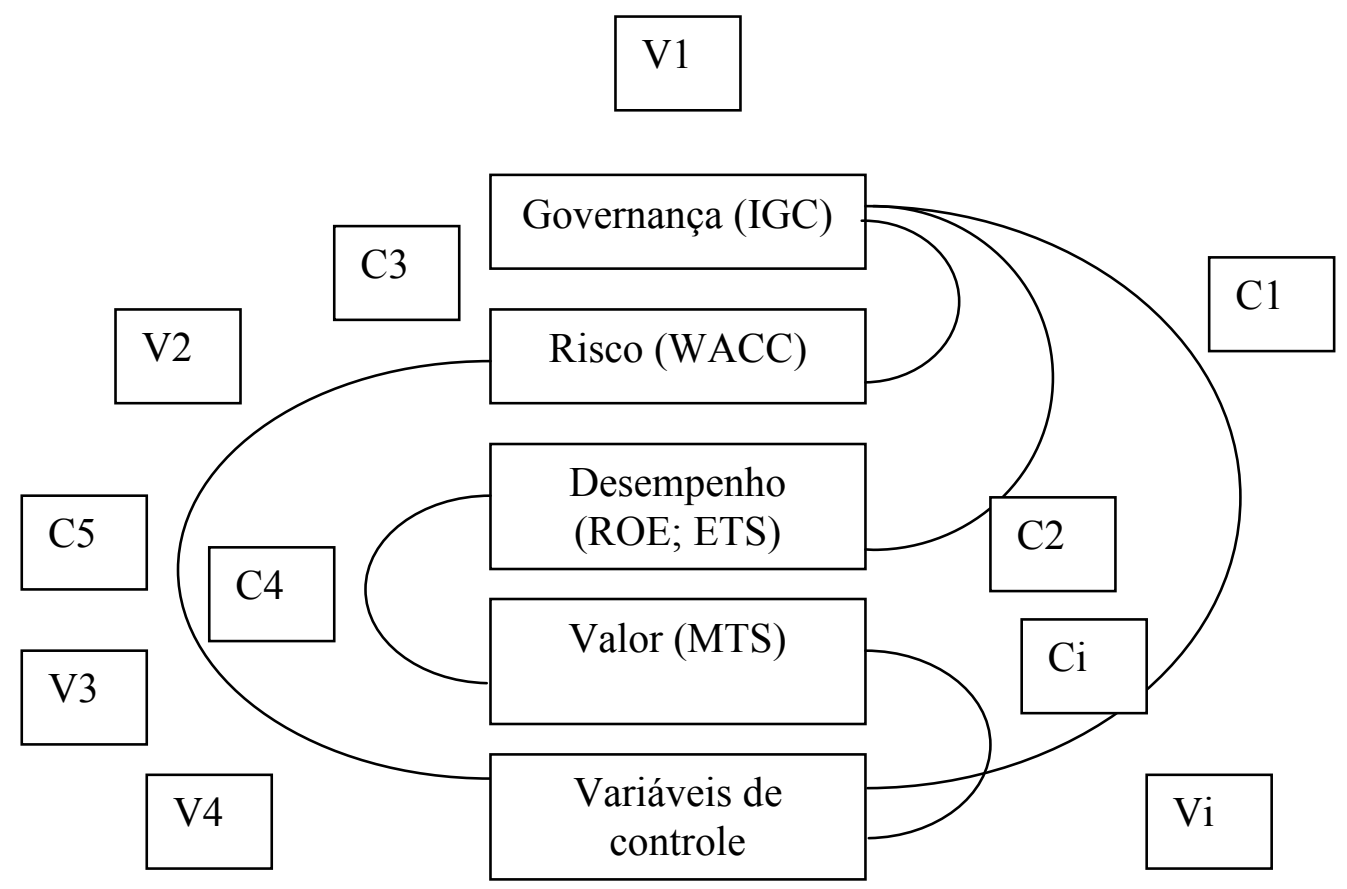

Figura 1: Diagrama de caminhos

As variáveis utilizadas estão identificadas a seguir: V1 = variância da variável governança; V2 = variância da variável risco; V3 = variância da variável desempenho; V4 = variância da variável valor; Vi = variância das variáveis de controle; $\mathrm{C} 1$ = covariância entre governança e valor; $\mathrm{C} 2$ = covariância entre governança e desempenho; C3 = covariância entre governança e risco; C4 = covariância entre risco e valor; C5 = covariância entre desempenho e valor; $\mathrm{Ci}=$ covariância entre variáveis de controle e valor.

Fonte: Os autores

\section{ANÁLISE DOS RESULTADOS DOS DETERMINANTES DA QUALIDADE DA GOVERNANÇA CORPORATIVA}

Do estudo desenvolvido com o método das regressões lineares múltiplas e posteriormente com o método das equações estruturais, verificou-se que, em resumo, governança está relacionada com as variáveis de risco e desempenho, incluindo nessa dimensão indicadores de valor, margem e rentabilidade. Contudo, outras variáveis se mostraram associadas à qualidade da governança corporativa praticada pelas companhias.

A inserção das variáveis relacionadas com risco, desempenho e valor das empresas amplia o espectro de abarangência de fatores que podem ter impacto direto com a qualidade da governança praticada pelas companhias abrasileiras. Isso é importante pois permite uma nova perspectiva sobre a interação endógena existente entre a variável governança e variáveis relacionadas com o comportamento das ações da empresa em bolsa como a volatilidade, os retornos e o valor de mercado. 
OS DETERMINANTES DA QUALIDADE DA GOVERNANÇA PRATICADA PELAS COMPANHIAS ABERTAS BRASILEIRAS

Os resultados dos modelos de regressões lineares e do modelo com a aplicação do método das equações estruturais podem ser encontrados na tabela 2.

Tabela 2: Resultados dos modelos de determinantes da governança corporativa Os símbolos $(*)$ correspondem a valor estatisticamente significativo a $20 \%$; (**) a 5\%; $(* * *)$ a $1 \% ;(* * * *)$ a $0,1 \%$ e $(* * * * *)$ a $0,001 \%$.

\begin{tabular}{|c|c|c|c|}
\hline $\begin{array}{l}\text { Variável } \\
\text { dependente } \\
\text { sqr(igc) }\end{array}$ & $\begin{array}{c}\text { Modelo } \\
\text { Completo - } \\
\text { MQO }\end{array}$ & $\begin{array}{c}\text { Modelo } \\
\text { Reduzido - } \\
\text { MQO }\end{array}$ & $\begin{array}{c}\text { Modelo de } \\
\text { Equações } \\
\text { Estruturais }\end{array}$ \\
\hline sqrbetasp & $\begin{array}{c}0,0502 \\
(0,4489)\end{array}$ & & 0,141 \\
\hline logidios & $\begin{array}{c}0,0220 \\
(0,4361)\end{array}$ & & $-0,019$ \\
\hline logvolat & $\begin{array}{c}-0,03543 * * \\
(0,0202)\end{array}$ & $\begin{array}{c}-0,0584 * * * * * \\
(0,0000)\end{array}$ & $-0,054$ \\
\hline sqrwacc & $\begin{array}{c}-0,4239 * * * * * \\
(0,0000)\end{array}$ & $\begin{array}{c}-0,3997 * * * * * \\
(0,0000)\end{array}$ & $-0,366$ \\
\hline logets & $\begin{array}{c}0,0292 * * * \\
(0,0031)\end{array}$ & $\begin{array}{c}0,0434 * * * * * \\
(0,0000)\end{array}$ & 0,118 \\
\hline logmts & $\begin{array}{c}0,0158 \\
(0,3244)\end{array}$ & & $-0,275$ \\
\hline sqrroa & $\begin{array}{l}-0,0131 \\
(0,3488)\end{array}$ & & $-0,009$ \\
\hline sqrroe & $\begin{array}{l}-0,0000 \\
(0,9987)\end{array}$ & & 0,018 \\
\hline logcap & $\begin{array}{c}0,0645 * * \\
(0,0158)\end{array}$ & $\begin{array}{l}0,0326^{*} \\
(0,1041)\end{array}$ & 0,141 \\
\hline sqrord & $\begin{array}{c}-0,0409 * * \\
(0,0247)\end{array}$ & $\begin{array}{c}-0,0198^{*} \\
(0,1573)\end{array}$ & $-0,054$ \\
\hline logcons & $\begin{array}{c}0,0007 \\
(0,9873) \\
\end{array}$ & $\begin{array}{l}0,0598 * \\
(0,0991)\end{array}$ & 0,058 \\
\hline logde & $\begin{array}{c}0,0190 \\
(0,1460) \\
\end{array}$ & & - 0,030 \\
\hline imob & $\begin{array}{c}-0,4000 * * * * * \\
(0,0000) \\
\end{array}$ & $\begin{array}{c}-0,4559 * * * * * \\
(0,0000) \\
\end{array}$ & $-0,155$ \\
\hline $\operatorname{loginv}$ & $\begin{array}{r}0,0059 \\
(0,3295) \\
\end{array}$ & & $-0,015$ \\
\hline logliq & $\begin{array}{l}-0,0059 \\
(0,5207) \\
\end{array}$ & & $-0,011$ \\
\hline logexp & $\begin{array}{c}0,0673 * * \\
(0,0231)\end{array}$ & $\begin{array}{c}0,0812^{* * *} \\
(0,0048)\end{array}$ & 0,038 \\
\hline logmtbv & $\begin{array}{c}-0,0882 * * * * \\
(0,0004) \\
\end{array}$ & $\begin{array}{c}-0,0373 * * \\
(0,0291) \\
\end{array}$ & 0,057 \\
\hline
\end{tabular}




\begin{tabular}{|c|c|c|c|}
\hline $\operatorname{adr} 23$ & $\begin{array}{l}0,0922^{*} \\
(0,0536)\end{array}$ & $\begin{array}{c}0,1291 * * * * \\
(0,0002)\end{array}$ & 0,186 \\
\hline logafin & $\begin{array}{c}-0,0593 * * * * \\
(0,0001)\end{array}$ & $\begin{array}{c}-0,422 * * * * * \\
(0,0000)\end{array}$ & $-0,115$ \\
\hline logaop & $\begin{array}{c}-0,0424 * * \\
(0,0319)\end{array}$ & $\begin{array}{c}-0,0332 * * \\
(0,0273)\end{array}$ & $-0,060$ \\
\hline $\mathrm{n} 2 \mathrm{~nm}$ & $\begin{array}{c}0,3624 * * * * * \\
(0,0000)\end{array}$ & $\begin{array}{c}0,4456 * * * * * \\
(0,0000)\end{array}$ & 0,186 \\
\hline n2nmadr23 & $\begin{array}{l}0,2101 * * \\
(0,0424)\end{array}$ & & $-0,721$ \\
\hline pri & $\begin{array}{l}-0,0170 \\
(0,7752)\end{array}$ & & $-0,021$ \\
\hline tam & $\begin{array}{c}0,0612 \\
(0,1535)\end{array}$ & $\begin{array}{l}0,0598 * * \\
(0,0137)\end{array}$ & 0,002 \\
\hline $\mathrm{C}$ & $\begin{array}{c}3,1792 * * * * * \\
(0,0000)\end{array}$ & $\begin{array}{c}3,14132 * * * * * \\
(0,0000)\end{array}$ & \\
\hline $\begin{array}{ll}\mathrm{R}^{2} & \text { não } \\
\text { ponderado } & \end{array}$ & 0,2450 & 0,2879 & \\
\hline $\mathrm{F}$ & 264959,0 & 4313,223 & \\
\hline $\mathrm{p}$-value & 0,0000 & 0,0000 & \\
\hline $\begin{array}{ll}\text { DW não } \\
\text { ponderado }\end{array}$ & 1,0981 & 0,9026 & \\
\hline Amostra & & & 431 \\
\hline$\lambda^{2}$ (Chi-square) & & & 20519,33 \\
\hline $\begin{array}{l}\text { Graus de } \\
\text { liberdade }\end{array}$ & & & 330 \\
\hline p-value & & & 0,000 \\
\hline
\end{tabular}

Fonte: Os autores

A partir dos resultados encontrados, constatou-se que empresas com maiores índices de governança corporativa estão associadas com: a) menores riscos - mensurados por log (volat) e sqr (wacc); b) maiores margens - mensurado por log (ets); c) maiores participações do controlador no capital da empresa - mensurado por log (cap); d) menores concentrações de ações com direito a voto por parte dos controladores - mensurado por sqr (ord); e) menores percentuais de imobilização de ativos - mensurado por imob; f) emissão de ADR níveis 2 ou 3 - mensurado por adr23; g) participação no Nível 2 e Novo Mercado da Bovespa - mensurado por n2nm; h) maiores conselhos - mensurado por $\log$ (cons); i) menores alavancagens financeira e operacional - mensuradas por log (afin) e log (aop); j) maior tempo de experiência societária - mensurado por log (exp); e k) maiores tamanhos - mensurado por tam.

A associação da qualidade da governança com menores riscos e maiores margens apenas confirmou os resultados obtidos anteriormente em Lameira (2007). Os resultados referentes ao relacionamento entre governança e risco estão em consonância com Drobetz et al. (2003), Ashbaugh et al. (2004) e Derwall e Verwijmeren (2007). Já na questão referente ao desempenho 


\section{OS DETERMINANTES DA QUALIDADE DA GOVERNANÇA PRATICADA PELAS COMPANHIAS ABERTAS BRASILEIRAS}

os resultados encontradsos entre governança e log (ets) se alinham com os trabalhos de Bai, Liu, Lu, Song e Zhang (2002), Beiner et al. (2004), Brown e Caylor (2004), Durnev e Kim (2005), Black, Jam e Kim (2006), no exterior, e Da Silva (2004), Da Silveira (2004), Leal e Da Silva (2005), no Brasil.

A relação negativa e significativa entre governança e as alavancagens operacional e financeira serviu apenas para confirmar a relação com as variáveis de risco por meio dessas variáveis de controle. Assim, verifica-se que a qualidade da governança também sofre impacto do grau de risco (operacional e financeiro) que a empresa incorre caso crie condições de alavancagem.

Pelo lado da relação entre governança e as variáveis de desempenho, observou-se que os resultados das relações entre governança e valor (log (mtbv) e $\log (\mathrm{mts}))$ não foram consistentes. Contudo como mencionado anteriormente constatou-se relação entre governança e log (ets) confirmada pelos resultados do teste de robustez.

A associação com maiores percentuais de ações, ou seja, com grande participação no capital preferencialista, confirmou a hipótese de que um controlador que tenha ações preferenciais deve evitar prejudicar os minoritários em vista de essa atitude também atingi-lo diretamente. A relação entre governança e menor concentração de ações ordinárias confirma a hipótese de que empresas com estruturas de propriedade menos concentradas melhoraram suas estruturas de controle e, por conseguinte, suas práticas corporativas de governança, em conformidade com Da Silva (2002) e Leal e Da Silva (2005).

Outra associação que se mostrou estatisticamente significativa foi a encontrada entre governança e menores percentuais de imobilização de ativos, confirmando a hipótese de que empresas com maiores percentuais de ativos não imobilizados têm de aumentar seu controle e, em decorrência, a qualidade das práticas de governança corporativa. Este raciocínio se encontra em alinhamento com Da Silveira (2004). Em sentido oposto, a intangibilidade é uma carcaterística que tornaria a empresa menos susceptível à melhoria de suas práticas de governanção.

O estabelecimento de programa de ADR níveis 2 ou 3 e a participação no Nível 2 ou Novo Mercado da Bovespa também se mostraram associadas com melhores níveis de qualidade de governança corporativa praticada pelas empresas também em alinhamento à Da Silveira (2004). Tais relações também confirmam a hipótese de que empresas que implementaram melhores práticas identificaram a oportunidade de aumentarem o espectro de investidores com a emissão de programas de ADR e a inserção no Nível 2 ou Novo Mercado da Bovespa. Esse resultado ratificou o entendimento assumido quando se incluíram a existência de programas de ADR ou condições inerentes à participação das companhias nos NDGC entre as práticas inseridas no índice de governança.

Por último, verificou-se que maior tamanho e mais tempo de vida societária como companhia aberta também são fatores determinantes da qualidade da governança praticada pelas empresas. Tais fatores são assumidos em diversas pesquisas como variáveis de controle e, por esse motivo, os resultados obtidos nessa pesquisa estão alinhados com Black et al. (2006), Leal e 
Da Silva (2005) entre outros. Quanto à relação entre tamanho e qualidade da governança pode-se mencionar que empresas com maior tamanho, identificados pelo montante de recursos em ativos são empresas com maior poder econômico para dispenderem em programas de melhoria da qualidade de informação prestada aos investidores e com um maior controle interno de suas operações. A respeito da relação entre qualidade da governança e tempo de vida societária podese intuir que as empresas com maior tempo em bolsa são empresas de maior robustez econômica, admitindo-se que a entrada em bolsa somente é uma condição relevante para a empresa quando esta atinge um determinado patrimônio e retornos adequados aos futuros custos marginais derivados de se tornar uma companhia aberta.

\section{5 - CONCLUSÕES}

Constatou-se, como novo conhecimento, que as variáveis de alavancagem (utilizadas como variáveis catalizadoras e potencializadoras do desempenho e do risco) possuem efeito sobre a qualidade da governança de sinal negativo. No mesmo sentido, o efeito das variáveis de risco (log (volat) e sqr (wacc)) também tem relação negativa com a qualidade da governança, enquanto a variável log (ets) mantém relação positiva com o referido nível de governança. $\mathrm{O}$ tempo de experiência societária e a participação no Nível 2 ou Novo Mercado da Bovespa também são novos fatores observados como geradores de impacto na qualidade da governança praticada.

Encontrou relação positiva e significativa entre tamanho do conselho e qualidade de governança. Entende-se que exista espaço para conselhos maiores, desde que uma pauta de maiores afazeres e políticas de valorização da atividade dos conselheiros na empresa, com a participação mais ativa e regular em comitês, seja posta em prática. Confirmaram-se, ainda, os efeitos do grau de concentração do capital total ou ordinário, o nível de imobilização da empresa e a existência de programa de ADR níveis 2 ou 3 como fatores que diferenciam a governança posta em prática pelas empresas.

Observa-se que o modelo de equações estruturais que avalia as relações entre as variáveis de risco, desempenho e de controle sobre a qualidade da governança praticada é uma forma adequada de se avaliar as potenciais relações de endogeneidade existentes entre governança e as demais variáveis.

Esta investigação encontrou resultados também compatíveis com os encontradas na investigação dos determinantes da qualidade de governança feita por Da Silveira et al. (2007).

Ficam como sugestão para pesquisas posteriores: a) o aumento do número de empresas componentes da amostra de modo que se possa inserir variáveis que segreguem empresas de setores de commodities e as empresas dos demais setores. Assume-se que as empresas do setor de commodities devem possuir maior transparência de suas operações devido ao fato de operarem com preços e custos internacionais conhecidos e amplamente divulgados; e b) a inserção de variável que promova diferenciação entre empresas pertencentes a setores regulamentados e não regulamentados, tendo em vista a expectativa de que os setores mais regulamentados deveriam apresentar menor influência da variável governança nas variáveis de desempenho e de risco. 
Além disso, também permanece como sugestão a investigação de quais serão os subíndices mais relevantes para cada setor.

\section{REFERENNCIAS}

ALCHIAN, A.; DEMSETZ, H. Production, information costs and economic organization. American Economic Review, New York, v. 62, n. 5, p. 777-795, dec. 1972.

AGUiAR, A. B. de; CORRAR, L. J.; BATISTELlA, F. D. Adoção de práticas de governança corporativa e o comportamento dos preços das ações na Bovespa: evidências empíricas. RAUSP, São Paulo, v. 39, n. 4, p. 338-347, outubro / novembro / dezembro, 2004.

ASHBAUGH, H. S.; COLLINS, D. W.; LAFOND R. Corporate governance and the cost of equity capital. Disponível em: $<$ http://ssrn.com/abstract=639681>. Acesso em: 01.ago.2007.

BAI, C.-E.; LIU, Q.; LU, J.; SONG, F. M.; ZHANG, J. Corporate governance and firm valuation in China. Disponível em: $<$ http://ssrn.com/abstract $=361660$ or doi:10.2139/ssrn.361660>. Acesso em: 01.ago.2007.

BEBCZUK, R. N. Corporate governance and ownership: measurement and impact on corporate performance and dividend policy in Argentina. Inter-American Development Bank, research network working paper R-516. Disponível em: $<$ http://ssrn.com/abstract=1815892>. Acesso em: 01.ago.2007.

BEINER, Stefan; DROBETZ, Wolfgang; SCMHID, Markus; ZIMMERMANN, Heinz. An integrated framework of corporate governance and firm valuation - evidence from Switzerland. European Corporate Governance Institute, working paper series, n. 34/2004. Disponível em: $<$ http://ssrn.com/abstract=489322>. Acesso em: 01.ago.2007.

BERLE, A.; MEANS, G. The modern corporation and private property. $10^{\text {th }}$. ed. New Jersey, Transaction Publishers, 2009.

BHAGAT, S.; JEFFERIS, Jr., R. H. The econometrics of corporate governance studies, $2^{\text {nd }}$. ed. Michigan. The MIT Press, mar. 2005.

BLACK, B. S.; JANG, H.; KIM, W. Does corporate governance predict firm's market values? Evidence from Korea. Journal of Law, Economics and Organization, v. 22, n. 2, p. 366-403, jan. 2006.

BÖHREN, O.; ODEGAARD, B. A. Governance and performance revisited. In: International Corporate Governance after Sarbanes-Oxley. $1^{\text {st }}$. ed. New Jersey, Paul Ali and Greg Gregoriou editors. Wiley - IEEE press, mar. 2006. 
BROWN, Lawrence; CAYLOR, Marcus. Corporate governance and firm performance. Disponível em: $<$ http://ssrn.com/abstract $=586423$ or doi:10.2139/ssrn.586423. Acesso em: 01.ago.2007.

CHO, M.-H. Ownership structure, investment, and the corporate value: an empirical analysis. Journal of Financial Economics. v. 47, n. 1, p. 103-121, jan. 1998.

CLAESSENS, S., DJANKOV, S., FAN, J.; LANG, L.. Disentangling the incentive and entrenchment effects of large shareholdings. Journal of Finance, v. 57, n. 2, pp. 2741-2771, dec. 2002.

DAMODARAN, A. Avaliação de investimentos: ferramentas e técnicas para a determinação do valor de qualquer ativo. $4^{\mathrm{a}}$ reimpressão. Rio de Janeiro. Qualitymark Editora, 2002.

DA SILVA, A. L. C. A influência da estrutura de controle e propriedade no valor de mercado, estrutura de capital e política de dividendos das empresas brasileiras de capital aberto. 2002. Tese (Doutorado em Administração de Empresas). Coppead, Rio de Janeiro, 2002.

DA SILVEIRA, A. Di M. Governança corporativa e estrutura de propriedade: determinantes e relação com o desempenho das empresas no Brasil. 2004. Tese (Doutorado em Administração de Empresas), USP, São Paulo, 2004.

DA SILVEIRA, A. Di M.; BARROS, L. A.; FAMÁ, R. Atributos corporativos, qualidade da governança corporativa e valor das companhias abertas no Brasil. In: V Encontro Brasileiro de Finanças, São Paulo, 18 e 19 de julho, anais, 2005.

DA SILVEIRA, A. Di M.; LEAL, R. P. C.; DA SILVA, A. L. C., BARROS, L. A. Determinants of Corporate Governance Quality in Brazil: Endogeneity Problems and Robust Estimation. In: XXXI Encontro da ANPAD, Rio de Janeiro, 22 a 26 de setembro, anais, 2007.

DERWALL, Jeroen; VERWIJMEREN, Patrick. Corporate governance and the cost of equity capital: evidence from GMI's governance rating. European Center for Governance Engagement, research note, jan. 2007.

DROBETZ, Wolfgang; SCHILLHOFER, Andreas; ZIMMERMANN, Heinz. Corporate governance and expected stock returns: evidence from Germany. WWZ/Departament of Finance, working paper $n^{\mathrm{o}} 2$, jan. 2003.

DURNEV, A.; KIM, H. To steal or not to steal: firm attributes, legal environment, and valuation. The Journal of Finance, New York, v. 60, n. 3, p. 1461-1493, jun. 2005. 
LAMEIRA, V. de J. Governança corporativa, risco e desempenho das companhias abertas brasileiras: uma análise do relacionamento entre as práticas de governança corporativa, o risco e o desempenho das companhias abertas brasileiras. 2007. 197 f. Tese (Doutorado em Admnistração de Empresas) - Instituto de Administração e Gestão da PUC-Rio, Pontifícia Universidade Católica do Rio de Janeiro, Rio de Janeiro, 2007.

LEAL, R. P. C.; DA SILVA, A. L. Carvalhal. Corporate governance, value and dividend payout in Brazil and Chile. Inter-American Development Bank. Research Network Working Paper R-516, oct. 2005.

ROWE, W. G.; MORROW Jr., J. L. A note on the dimensionality of the firm financial performance construct using accounting, market, and subjective measures. Canadian Journal of Administrative Science, v. 16, n. 1, p. 58-71, mar. 1999. 
Apêndice - Racionalidade e critérios utilizados para a elaboração do índice de governança corporativa

A - Estrutura de propriedade e controle

Questão $1-\mathrm{O}$ percentual das ações com direito a voto do controlador é igual ou menor que o percentual do grupo controlador em relação ao total de ações da companhia?

Critério para pontuação - Atribuiu-se um ponto para as empresas em que o controlador tenha um percentual do capital total, igual ou maior do que o percentual de ações ordinárias. Quando a empresa somente emitiu ações ordinárias, o percentual de ordinárias do controlador é igual ao do capital total, sendo conferido um ponto para a companhia.

Questão 2 - A percentagem de ações não votantes é menor que $20 \%$ do total do capital?

Critério para pontuação - Atribuiu-se um ponto para as empresas em que o percentual de ações preferenciais fosse menor que $20 \%$ do capital total. Assim sendo, quando a empresa somente possui ações ordinárias também se confere um ponto para a companhia.

Questão 3 - A empresa não tem estrutura piramidal de controle ou o controle é direto.

Critério para pontuação - Conferiu-se um ponto para as empresas em que somente existe a abertura de um subnível para qualquer um dos investidores que aparecem na lista de acionistas com mais de $5 \%$ do capital da empresa no formulário IAN. Admite-se, portanto, que o investidor da empresa possa ser uma empresa de participação que no momento seguinte divulgue a lista de seus acionistas controladores.

Questão 4 - Observando o estatuto da companhia, pelo menos uma das afirmativas é verdadeira: a) cada ação vale um voto?; b) as ações preferenciais têm direito de voto em decisões importantes da companhia?

Critério para pontuação - Atribuiu-se um ponto para as empresas que emitiram somente ações ordinárias; ou para empresas nas quais exista pelo menos uma das condições de voto mencionadas anteriormente para os acionistas detentores de ações preferenciais. Confirma-se a existência da possibilidade do exercício do direito de voto no estatuto social da empresa.

B - Nível de disclosure das informações e benefícios privados de controle Questão 5 - A companhia tem demonstrações em US-GAAP ou IAS-GAAP?

Critério para pontuação - Foi atribuído um ponto para as empresas que divulgaram os balanços em padrão contábil internacional. Assim, todas as empresas que têm programas de ADR obtiveram pontuação, pois necessitam compatibilizar os resultados contábeis obtidos no padrão nacional com os padrões contábeis americanos e disponibilizam tais informações no formulário 20-F, possível de ser acessado no site da SEC. As informações referentes a esse quesito foram ratificadas junto aos dados de companhias com ADR, colhidos no site www.cvm.gov.br, da CVM, e no site www.adr.com, do banco J. P. Morgan.

Questão 6 - A companhia não apresenta contrato de mútuo nem utiliza a rubrica lucros acumulados como reserva de lucros sem ter disclosure da existência de orçamento de capital como destinação desses recursos.

Critério para pontuação - Atribuiu-se um ponto para as empresas que não apresentam contratos de mútuo ou retenção de lucros na rubrica de lucros acumulados.

$\mathrm{C}$ - Auditoria e conselho fiscal

Questão 7 - A auditoria é feita por uma das cinco maiores empresas de auditoria em atividade no Brasil?

Critério para pontuação - Atribuiu-se um ponto para as empresas cujas DF foram auditadas por uma das auditorias retromencionadas. 


\section{OS DETERMINANTES DA QUALIDADE DA GOVERNANÇA PRATICADA PELAS COMPANHIAS ABERTAS BRASILEIRAS}

Questão 8 - As Informações Financeiras Trimestrais (os ITRs) da companhia são entregues dentro do prazo e NÃO contêm ressalvas?

Critério para pontuação - Atribuiu-se um ponto para as empresas cujas informações trimestrais tenham sido entregues dentro do prazo e sem ressalvas por parte dos auditores.

Questão 9 - A sociedade NÃO teve parecer de auditoria com discordância de opinião ou ressalva nas suas demonstrações financeiras (DF).

Critério para pontuação - As companhias cujos pareceres de auditoria não contiveram ressalva ou discordância de opinião receberam um ponto.

Questão 10 - A empresa tem conselho fiscal permanente?

Critério para pontuação - As companhias cujos IAN continham informações referentes à existência de conselho fiscal permanente, sendo essa observação ratificada por disposição nesse sentido, contida no estatuto social, obtiveram um ponto.

D - Conselho de administração e política de remuneração

Questão 11 - Os administradores têm participação nos lucros?

Critério para pontuação - As companhias cujos IAN continham informações referentes à participação dos administradores no lucro da sociedade obtiveram um ponto.

Questão 12 - A empresa tem mais de 50\% de conselheiros independentes, conforme reporta o IAN?

Critério para pontuação - As companhias cujos IAN continham informações referentes à existência de mais de $50 \%$ de conselheiros não eleitos pelo controlador obtiveram um ponto.

Questão 13 - O conselho tem entre cinco e nove membros?

Critério para pontuação - As empresas cujos conselhos detinham um número de membros no intervalo aberto compreendido entre cinco e nove membros receberam um ponto.

Questão 14 - Presidente do conselho NÃO é diretor ou controlador da empresa?

Critério para pontuação - Conferiu-se um ponto para as empresas nas quais o cargo de presidente do conselho não fosse ocupado pelo controlador, familiar ou pelo presidente da companhia.

Questão 15 - A empresa possui qualquer tipo de comitê evidenciado em seus documentos societários ou em seu website?

Critério para pontuação - As companhias cujos estatutos sociais continham informações referentes à constituição, ou mesmo à possibilidade de serem constituídos comitês por parte dos conselhos de administração, obtiveram um ponto.

Questão 16-O diretor financeiro não é diretor de relações com investidores?

Critério para pontuação - Conferiu-se um ponto para as empresas em que as atribuições do diretor de relações com investidores não fossem acumuladas com as funções de diretor financeiro.

E - Relacionamento com investidores

Questão 17 - A sociedade tem investidor institucional com mais de 5\% do capital da empresa?

Critério para pontuação - Atribuiu-se um ponto para as empresas que possuíam investidor institucional com participação igual ou superior a $5 \%$ do capital total da empresa. Assumiu-se que as empresas com investidores institucionais que fossem acionistas minoritários e não participantes do grupo de controle ganhariam um ponto. Dessa forma, somente não foi atribuído ponto aos investidores institucionais que fossem controladores da empresa ou que não detivessem uma participação maior ou igual a 5\%.

Questão 18 - A empresa NÃO teve problemas com investidores na CVM nos últimos cinco anos, NEM esteve inadimplente na entrega de informações OU teve de refazer suas demonstrações financeiras? 
Critério para pontuação - Atribuiu-se um ponto para as empresas que não tiveram problemas com investidores, nem estiveram inadimplentes ou necessitaram refazer suas demonstrações financeiras no período investigado.

Questão 19 - A companhia tem mais de 25\% de suas ações em free-float?

Critério para pontuação - Atribuiu-se um ponto para as empresas que possuíam mais de $25 \%$ das ações disponíveis para negociação no mercado.

Questão 20 - A empresa oferece tag along além do exigido pelo dispositivo legal?

Critério para pontuação - As empresas com tag along diferenciado obtiveram um ponto nesse quesito. As informações referentes a essa questão foram obtidas junto ao site da Bovespa na seção relativa às empresas, no quesito "investidores", cujo subitem é "empresas com tag-along". Tal procedimento foi relevante para a obtenção de dados fidedignos relacionados a esse item, pois diversas companhias estendem esse direito aos minoritários ordinaristas e/ou preferencialistas, mas tal informação não se encontra no estatuto social da empresa no ano em que ocorreu o evento que deliberou a respeito dessa prática. 